\title{
ENETS Consensus Guidelines Update for Neuroendocrine Neoplasms of the Jejunum and Ileum
}

\author{
$\begin{array}{lllll}\text { B. Niederle } & \text { U.-F.Pape } & \text { F. Costa } & \text { D. Gross } & \\ & \text { F. Kelestimur } & \text { U. Knigge } & \text { K. Öberg } & \end{array}$ \\ M. Pavel $^{\text {b }} \quad$ A. Perren ${ }^{\text {h }} \quad$ C. Toumpanakis ${ }^{i} \quad$ J. O'Connor ${ }^{j} \quad$ D. O'Toole ${ }^{k} \quad$ E. Krenning ${ }^{\prime}$ \\ N. Reed ${ }^{m}$ R. Kianmanesh ${ }^{n}$ all other Vienna Consensus Conference participants
}

${ }^{a}$ Department of Surgery, Medical University of Vienna, Vienna, Austria; ${ }^{b}$ Department of Hepatology and Gastroenterology, Campus Virchow Klinikum, Charité Universitätsmedizin Berlin, Berlin, Germany; ${ }^{\circ}$ Centro de Oncologia, Hospital Sírio Libanês, São Paulo, Brazil; ' Department of Endocrinology and Metabolism, Hadassah University Hospital, Mevasseret Tsion,

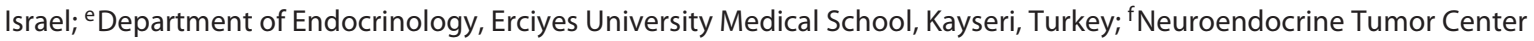
of Excellence, Rigshospitalet, Copenhagen University Hospital, Copenhagen, Denmark; ${ }^{9}$ Department of Medical Sciences, Endocrine Oncology Unit, University Hospital, Uppsala, Sweden; ${ }^{\mathrm{h}}$ Institute of Pathology, University of Bern, Bern, Switzerland; 'Neuroendocrine Tumour Unit, Royal Free Hospital, London, UK; 'Department of Clinical Oncology, Institute Alexander Fleming, Buenos Aires, Argentina; ${ }^{k}$ National NET Centre, St. Vincent's University and Department of Clinical Medicine, St. James Hospital and Trinity College, Dublin, Ireland; 'Department of Internal Medicine, Division of Nuclear Medicine, Erasmus Medical Center,

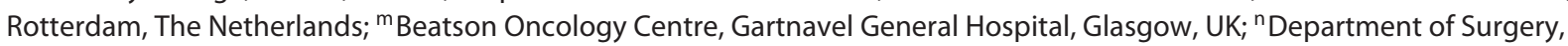
CHU Robert Debré, Reims, France

\section{Introduction}

Neuroendocrine neoplasms (NENs) of the small intestine (i.e. the ileum and jejunum; Si-NENs) [1] comprise at least the third largest subgroups of NENs within the gastroenteropancreatic system [2]. Because of a better knowledge of the molecular and cell-biological aspects as well as the clear pathohistological characterization of this tumor entity [3], a worldwide overall increase of NENs is reported [4]; the location in the small intestine reaches in some publications the largest absolute number $[5,6]$.

Si-NENs derive from serotonin-producing enterochromaffin cells. The biology of these tumors is different from other NENs of the digestive tract, characterized by a low proliferation rate [the vast majority are grade 1 (G1) and G2], they are often indolent; G3 tumors are excep- tional. However, classified as G1 or G2, Si-NENs are often discovered at an advanced disease stage - regional disease (36\%) and distant metastasis (48\%) are present - and percutaneous biopsy of a liver lesion is often the diagnostic procedure performed $[2,7]$.

Previous ENETS guidelines $[1,8,9]$ have discussed extensively the clinical symptomology, diagnosis and treatment of localized, regionalized as well as distant Si-NENs. This fourth edition of the ENETS guidelines is an update of the third version for the management of patients with Si-NENs published in 2012 [1] in order to further standardize and improve the early diagnosis and treatment of Si-NEN patients. This guideline deals with non-meta-

For an alphabetical list of all other Vienna Consensus Conference participants, see Appendix.

\section{KARGER}

E-Mail karger@karger.com

www.karger.com/nen
(C) 2016 S. Karger AG, Basel

$0028-3835 / 16 / 1032-0125 \$ 39.50 / 0$
Bruno Niederle, MD

Section of Endocrine Surgery, Division of General Surgery, Department of Surgery Medical University, Währinger Gürtel 18-20 AT-1090 Vienna (Austria)

E Mail bruno.niederle@meduniwien.ac.at 
static NENs originating from the small bowel, originally described as 'carcinoid' tumors by Oberndorfer in 1907 [10].

This update does not include metastatic disease which is covered in a separate paper of this issue; this other paper also discusses guidelines for medical and other treatment options of the 'carcinoid syndrome', since this occurs almost exclusively when the tumor is metastatic. The carcinoid heart disease (CHD or Hedinger syndrome), however, is covered in this paper, since early recognition and treatment is important for this complication of the carcinoid syndrome.

\section{Epidemiology and Prognosis}

Si-NENs are an overall relatively rare entity with a reported incidence between 0.32/100,000 in England [11], $0.33 / 100,000$ in Japan [12], $0.67 / 100,000$ in the USA [6], $0.81 / 100,000$ in Norway [13] and 1.12/100,000 in Sweden [14] according to the most recent literature. Malignant Si-NENs have been reported with an incidence of $0.29 / 100,000$ [2]; in this study, malignant Si-NENs made up approximately half of all NENs, while other studies have shown lower numbers, i.e. $20-35 \%[1,6,13]$. The mean age at initial diagnosis is in the late 50 s in several cohorts, with the majority of cases occurring in the 7th decade [12, 15-17]. The incidence of Si-NENs has not shown a gender preference in some series $[11,15,17]$ with a slight male preponderance in others $[12,16,18]$. While the incidence of Si-NENs may be lower in persons of Asian descent $[6,12]$, it seems to be higher in African Americans in the SEER data-base [6]. Si-NENs constitute up to one third or even half of all small bowel neoplasms $[2,16]$. The 'true' incidence of Si-NENs in post-mortem studies is much higher $(1.22 / 100)$ and suggests that these NENs may be much more abundant at early or very early stages but do not manifest themselves clinically and are not diagnosed during life [19].

The prognosis of Si-NENs depends on both staging and grading, which is reflected in the WHO classification of 2010 [20]. This has also been shown in a recent study in which the Ki-67 grading system as well as TNM staging for Si-NENs have been validated; Jann et al. [21] reported 5 -year tumor-specific survival rates for jejuno-ileal NENs from an oncological cohort of $100 \%$ for stage I and II, $97.1 \%$ for stage III and $84.8 \%$ for stage IV Si-NENs. Grading-dependent 5-year tumor-specific survival rates are $93.8 \%$ for G1, $83.0 \%$ for G2 and $50.0 \%$ for the very rare G3 Si-NENs [21]. The SEER analysis for Si-NENs per- formed by Boudreaux et al. revealed 5-year overall survival rates of approximately $72 \%$ for locoregional spread and approximately $55 \%$ for NENs with distant metastases [22]. In the Spanish NET registry, 5-year survival for the whole cohort of 'enteric carcinoid tumors' was $77.6 \%$ [15], and this figure was only $61 \%$ in the Netherlands Cancer Registry (NCR) reported approximately 10 years earlier [23]. The SEER data do not suggest a significant survival difference between different ethnicities [6]. The prognosis for Si-NENs is, thus, considerably better than for other small intestinal neoplasms such as lymphomas, adenocarcinomas and sarcomas [16]. In the older patient group of more than 60 years at initial diagnosis, the outcome figures may be worse as was suggested by an analysis of the population-based Florida Cancer Data System (FCDS) [24], but this may not be exclusively related to NENs but rather other secondary neoplasms or other agerelated causes of death [18].

Although recent data [25] suggest better overall or tumor-specific outcome figures, the data sets are not completely comparable as they are analyzed at different tumor stages. However, as has been suggested by Yao et al. [6], the overall outcome has probably improved over the last 25 years which may be related to better diagnosis, effective treatment options and multimodal sequential or simultaneous treatments. This aspect, however, has not been specifically shown by every study [18], and will also undoubtedly be very hard to prove.

Localized mesenteric lymph node metastases, distant abdominal lymph node metastases, liver tumor burden and extra-abdominal metastases seem independent prognostic factors by multivariate analysis [26].

\section{Minimal Consensus Statement on Epidemiology and Prognosis}

The former terminology of midgut and hindgut origin is inaccurate and hence these tumors are classified as jejuno-ileal, appendiceal, cecal, colonic or rectal NENs. The clinical incidence of Si-NENs is considerably lower than the incidence at autopsy (approx. 1:100). It is probably higher than stated earlier in the literature. Figures from the SEER and other registries indicate a significant rise of the reported annual incidence of $0.67-$ $0.81 / 100,000 /$ year for Si-NENs. The incidence rate may be considerably lower in Asia with $0.20 / 100,000$ /year as suggested by Japanese data. Si-NENs represent 30-50\% of all small bowel neoplasms. The incidence rates have increased in more recent years. The average age at diagnosis for patients with these tumors is between 60 and 65 years. According to the literature, there is a slight male preponderance, and there are some ethnic differences. African Americans have a higher incidence rate than Caucasians.

$\mathrm{Ki}-67$ grading is an important prognostic stratifier and is therefore mandatory in pathological reporting. Survival rates 
strongly depend on histopathological WHO classification and TNM stage: 5-year overall survival rates for all stages reach between 50 and $60 \%$. In Si-NEN patients with locally advanced disease, 5-year survival reaches $80-100 \%$, and in patients with regional lymph node involvement it reaches $70-80 \%$ (stages IIIIa). Survival in stage IV disease patients lies between 35 and $80 \%$. Series presenting analyses from more recent data collections observe even more favorable outcome.

\section{Clinical Presentation}

Nonspecific symptoms (vague abdominal pain or weight loss) were evident in $37 \%$ of all Si-NEN patients. Retrospectively, specific clinical symptoms either local (e.g. local stenosis or melena) or systemic (e.g. diarrhea or flushing) were reported in $21.5 \%$, respectively [7]. Landerholm et al. [14] reported that even Si-NENs with distant metastasis may present without symptoms and the 'carcinoid syndrome' is infrequently seen. Therefore, it is recommended that primary-care physicians should keep in mind NENs and their vague nonspecific clinical features and start appropriate diagnostic testing early [27].

$\mathrm{Si}-\mathrm{NENs}$ are frequently detected only when searching for a primary tumor in either asymptomatic or symptomatic patients (e.g., with carcinoid syndrome) with metastases; they can rarely be found incidentally, for example on screening colonoscopy in the terminal ileum or on a CT scan performed in another clinical context. The most frequent clinical symptom from single- or multi-centric series as well as from population-based data sources is nonspecific abdominal pain $[7,14,28-31]$ which may be due to various reasons: dysmotility of the small bowel wall, small bowel obstruction, intermittent mesenteric ischemia caused by mesenteric root fibrosis, but also functional causes such as secretory diarrhea and bacterial overgrowth. Other nonspecific symptoms such as weight loss, fatigue and (rarely) fever of unknown origin may also occur. Tumor-mass-related symptoms due to bowel obstruction with nausea and vomiting, jaundice in case of metastatic cholestasis and even GI bleeding may also occur, but in a smaller proportion of patients [7, 14, 28-31]. The desmoplastic reaction leading to visceral fibrosis may culminate in small bowel ischemia or hydronephrosis from some degree of retroperitoneal fibrosis, although these are rare problems.

Tumor-specific hormone-hypersecretion-related symptoms from the carcinoid syndrome comprise secretory diarrhea (60-80\%), flushing (60-85\%) and intermittent bronchial wheezing (which is frequently not clinically apparent; $<10 \%$ ) and most importantly right heart

ENETS Consensus Guidelines Update for

NENs of the Jejunum and Ileum valve fibrosis with $\mathrm{CHD}$ (Hedinger syndrome; in up to $20 \%)[18,29-31]$. These manifestations are always associated with metastatic disease and by far most often with liver metastasis, which allows bypassing of hepatic clearance of serotonin from the portal circulation $[28,31,32]$. There is no evidence that the carcinoid syndrome per se, independent of metastatic disease, has an influence on prognosis [21] except for clinically manifest right-sided heart failure of CHD (see below).

A 'carcinoid crisis' is a severe and potentially fatal exacerbation stemming from hormone or peptide hypersecretion, leading to symptoms and signs often provoked by anesthesia or invasive procedures such as surgery [33]. The clinical picture includes flushing, hypo- or hypertension, diarrhea, severe bronchospasm and cardiac arrhythmias.

\section{Minimal Consensus Statement on Clinical Presentation}

Abdominal pain is the most frequent initial symptom in patients presenting with Si-NENs from the small bowel (often assimilating irritable bowel syndrome). The carcinoid syndrome is seen in approximately $20-30 \%$ of patients with metastases, this percentage is higher than previously stated. Small bowel ischemia can be another cause of diarrhea and pain besides hormone-hypersecretion-related diarrhea. Flushing and diarrhea are thought to be the cardinal symptoms in functional tumors and are equally $(80 \%)$ present. It is emphasized that the carcinoid syndrome is usually seen in patients with liver metastases (in 95\% of all patients), but excess tachykinin or serotonin production from retroperitoneal metastases or ovarian tumors/metastases can bypass the liver, enter the systemic circulation and cause the typical carcinoid syndrome (in up to $5 \%$ of the patients).

\section{Imaging}

Cross-sectional imaging by either CT following modern protocols (3-phase contrast-enhanced multi-slice CT) or MRI (also with the use of contrast media) is the cornerstone of indirect imaging of the abdomen for initial staging as well as preoperative diagnosis $[34,35]$. By this approach, the primary tumor may sometimes be imaged, but lymph node and/or distant metastases can regularly be either detected or ruled out, respectively. In the case of an unknown primary tumor, thoracic scanning (preferably with CT) may also be necessary to either detect or rule out a bronchial primary NEN. CT or MR enteroclysis may provide additional benefit for primary tumor detection in the small intestine with very good sensitivities and specificities in institutions where either 
of them is available [36, 37]. Transabdominal ultrasonography may be used for screening of hepatic metastases with good results [38], but the technique is investigator dependent; in individual cases, transabdominal ultrasonography of the small bowel with high-frequency probes (10 or $12 \mathrm{MHz}$ ) may also detect a small intestinal primary tumor and/or mesenteric lymph node metastases. However, for long-term follow-up purposes and reliable comparability, CT or MRI provides a better investigator-independent basis.

Direct visualization may be possible with regular colonoscopy if the tumor is prolapsed through the ileocecal valve into the colon, or if intubation of the ileum is performed during the investigation. For investigations of more proximal parts of the ileum or of the jejunum, the newer modalities of enteroscopy including video-capsule endoscopy (VCE) [39] or double-balloon enteroscopy [40] may be effective, although their role in routine staging still has to be established, and they are not widely available. The use of VCE as part of the diagnostic work-up in selected patients presenting with metastatic NENs of unknown primary is suggested. However, the clinical utility of this technology requires clearer definition [41]. There are no data on potential procedural risks of these methods in NEN which should always be weighed against the benefits of tumor localization and/or even histological confirmation by luminal biopsy. At least, in the case of impending small bowel occlusion, VCE is absolutely contraindicated.

Somatostatin receptor imaging (SRI) of Si-NENs depends on the presence of somatostatin receptors in NEN, particularly of subtype 2 (SSR-2), which is the receptor to which the currently used ligands for these modalities bind with the highest affinity. Linked to the ligand are either radionuclides that can be detected by somatostatin receptor scintigraphy (SRS; e.g. ${ }^{111}$ Indium) or by positron emission tomography (PET; e.g. ${ }^{68}$ Gallium) scanning [42-54]. For Si-NEN PET scanning, the use of ${ }^{18}$ fluorodeoxyglucose cannot be recommended, since it has a low sensitivity for well-differentiated low-grade NEN, which comprise by far the majority of Si-NENs. However, it is recommended in G3 NENs independent of the location of the tumor. Other newer traces such as ${ }^{11}$ carbon-5-hydroxytryptophane or ${ }^{18}$ fluoro-dihydroxyphenylalanine (DOPA) have shown promising results but are even less available and await further study $[49,55]$. SRI has sensitivities of approximately $90 \%$ for primary/nodal SiNENs and of $>95 \%$ for liver metastases and is, therefore, an important tool for initial staging as well as for followup. ${ }^{68} \mathrm{Ga}$ PET, preferably with simultaneous contrast CT (functional imaging), see figure 1 , may be even more sen- sitive and change management in an additional $20-30 \%$ of the cases. Particularly for the detection of small tumors within the jejuno-ileum, as well as for the preoperative exclusion of distant metastases not detected by other direct or indirect imaging modalities, PET scanning may be useful, but this requires further prospective studies.

${ }^{68} \mathrm{Ga}$-DOTATOC PET/CT was found to be more useful to ${ }^{111}$ In-DTPA octreotide SPECT/CT when searching for a primary NEN in patients with unknown or suspected disease [56].

SRI may also be useful in detecting silent or clinically suspected bone metastases, which represent the fourth most frequent metastatic localization (after lymph nodes, liver and the lungs in descending frequency) [17, 30]; although conventional bone scintigraphy using $99 \mathrm{~m}$-technetium-DPD scintigraphy may also be useful [57].

A rational step-wise approach of diagnostic modalities, as suggested in figure 1 , is recommended to make the optimal use of the available methods and limited resources, with the least invasive methodology for the patient and the most effective outcome for patient management.

\section{Minimal Consensus Statement on Imaging}

In the search for a primary tumor, cross-sectional imaging with CT and/or MRI should be followed by ${ }^{68} \mathrm{Ga}$-DOTATOC PET in combination with native or preferably 3-phase contrastenhanced CT (functional imaging) or if not available SRS SPECT/ CT. In general, fusion imaging with CT is always preferable. Newer PET imaging techniques may be useful but require a cyclotron and are unlikely to become generally available. ${ }^{18}$ Fluorodeoxyglucose PET is not usually useful in these lower-grade tumors. If localizing a primary tumor is required in surgical candidates prior to bowel resection, either CT-/MR-water enteroclysis or endoscopic techniques such as VCE or double-balloon enteroscopy may be used according to local expertise, but potential risks need to be weighed against benefits such as precise preoperative localization particularly of multi-centric NENs. Colonoscopy should be performed because it may detect primary tumors in the distal ileum and is necessary to rule out synchronous neoplastic disease (particularly colorectal cancer). For cardiac diagnostics to investigate for $\mathrm{CHD}$, please see the section below.

\section{Laboratory Tests}

Serum chromogranin A $(\mathrm{CgA})$ remains a relatively sensitive marker for NENs of all origins including SiNENs [58-60]. CgA has also more recently been shown to prognostically predict significantly differing groups, with higher levels of $\mathrm{CgA}$ indicating a worse prognosis, probably related to increased tumor cell mass [61, 62]. For longitudinal follow-up purposes, it is important to 


\begin{tabular}{|c|c|c|c|c|c|c|}
\hline \multicolumn{7}{|c|}{ Clinical diagnosis: incidental or symptomatic } \\
\hline \multicolumn{3}{|c|}{$\begin{array}{l}\text { Abdominal surgery } \\
\text { (incl. emergency) }\end{array}$} & \multicolumn{2}{|c|}{$\begin{array}{l}\text { Abdominal } \\
\text { sonography }\end{array}$} & \multicolumn{2}{|c|}{ Endoscopy } \\
\hline \multicolumn{3}{|c|}{ Primary tumor and/or Ln mts } & \multicolumn{2}{|c|}{ Liver lesions - biopsy } & \multicolumn{2}{|c|}{ (Jejuno-) ileal primary tumor } \\
\hline \multicolumn{7}{|c|}{ Histopathological diagnosis } \\
\hline \multicolumn{7}{|c|}{$\begin{array}{l}\text { - Hematoxylin-eosin staining } \\
\text { - Immunohistochemical staining: chromogranin A (CgA), synaptophysin - positive for siNEN: serotonin; cdx-2 } \\
\text { - Grading: Ki67 index; mitotic index }\end{array}$} \\
\hline \multicolumn{4}{|c|}{ Clinical staging } & \multicolumn{3}{|c|}{ Functionalty } \\
\hline \multicolumn{4}{|c|}{$\begin{array}{c}\text { Imaging } \\
\text { Cross-sectional (CT, MRI) or functional imaging } \\
\text { (G1 andG2: SSR-PET-CT; G3: FDG-PET-CT }\end{array}$} & \multicolumn{3}{|c|}{$\begin{array}{l}\text { Biochemistry } \\
\text { CgA } \\
\text { 5-HIAA }\end{array}$} \\
\hline \multicolumn{3}{|c|}{ Primary tumors with/without mets } & No primary & \multirow{2}{*}{ Normal } & \multicolumn{2}{|c|}{ Elevated } \\
\hline \multirow[b]{3}{*}{$\begin{array}{c}\text { Primary } \\
\text { only }\end{array}$} & \multirow[b]{3}{*}{ Ln-mets } & \multirow{3}{*}{$\begin{array}{l}\text { Distant mets } \\
\text { (distant Lns, } \\
\text { liver, bone, } \\
\quad \text { lung) }\end{array}$} & \multirow{3}{*}{$\begin{array}{ll}\text { - } & \text { Capsule } \\
\text { endoscopy } \\
\text { - } \\
\text { Double-balloon } \\
\text { enteroscopy } \\
\text { - Colonoscopy* }\end{array}$} & & Asymptomatic & Symptomatic \\
\hline & & & & Nor & ctioning & Functioning \\
\hline & & & & \multicolumn{3}{|c|}{$\begin{array}{l}\text { Echocardiography } \\
\text { NT-pro-BNP } \\
\text { (to exclude or confirm): } \\
\text { Carcinoid heart disease } \\
\text { (Hedinger's Syndrom) }\end{array}$} \\
\hline
\end{tabular}

Fig. 1. Diagnostic algorithm of Si-NENs. Mets = Metastasis; $\mathrm{Ln}=$ lymph nodes; NT-pro-BNP = B-type natriuretic peptide; 5HIAA - 5-hydroxyindoleacetic acid is a biochemically determinable metabolite of serotonin, a specific mediator of the carcinoid syndrome; CgA - chromogranin A is non-specific for the carci-

note that absolute $\mathrm{CgA}$ values may differ significantly between different assays [63], and therefore it is recommended to perform repeated measurements in the same laboratory or at least with the same assay whenever possible. Furthermore, the differential diagnosis of elevated $\mathrm{CgA}$ values such as in patients on proton pump inhibitors (PPIs), with chronic atrophic gastritis, chronic renal failure, liver cirrhosis or congestive heart failure, as well as other CgA-secreting neoplasms (e.g. hepatocellular carcinoma, medullary thyroid carcinoma) needs to be considered when CgA values are interpreted [64-66]. CgA may signal NEN recurrence after successful curative resection early in patients with a small tumor burden [59, 67].

Endocrine tumors of the jejuno-ileum produce serotonin and elevated 24-hour urinary 5-hydroxy indole acetic acid (5-HIAA) levels as a product of the metabolism of serotonin $[68,69]$. 5-HIAA has a sensitivity of up to $100 \%$ and a specificity of $85-90 \%$ for detecting a carcinoid syndrome, and a sensitivity of $70-75 \%$ and a noid syndrome; SSR = somatostatin receptor; $\mathrm{PET}=$ positron emission tomography; CT = X-ray computed tomography; FDG = fluorodeoxyglucose (18F). *If not performed previously: colonoscopy including the terminal ileum and to exclude a secondary primary. specificity of close to $100 \%$ for predicting a primary tumor in the jejuno-ileum $[58,60]$. Urinary 5-HIAA should be collected with strict dietary restrictions to avoid false positive levels [70]. Serum serotonin determinations are less sensitive and specific and are, therefore, not recommended; serotonin measurements in platelets, where serotonin is stored depending on its availability in the systemic circulation, may be even more sensitive, but is not widely available and therefore currently impractical [69].

\section{Minimal Consensus Statement on Laboratory Tests}

The minimally required biochemical tests include plasma $\mathrm{CgA}$ and urinary 5-HIAA. These tests should be performed at the first visit and then for follow-up or on suspicion of NEN recurrence or progression. Newer markers, either biochemical or based on circulating NEN cells, require further validation. Neuron-specific enolase has no role for the diagnosis of these almost always well- to moderately differentiated NEN (G1/2 NET). 
Table 1. TNM classification, staging and grading of Si-NENs according to the ENETS guidelines and UICC classification [3, 20, 72]

a TNM classification of Si-NENs

$\begin{array}{ll}T \text { - Primary tumor } \\ \mathrm{x} & \text { Primary tumor cannot be assessed } \\ 0 & \text { No evidence of primary tumor } \\ 1 & \text { Tumor invades mucosa or submucosa and size } \leq 1 \mathrm{~cm} \\ 2 & \text { Tumor invades muscularis propria or size }>1 \mathrm{~cm} \\ 3 & \text { Tumor invades subserosa } \\ 4 & \text { Tumor invades peritoneum/other organs } \\ & \text { for any T add }(\mathrm{m}) \text { for multiple tumors }\end{array}$

$N$ - Regional lymph node metastasis

$\mathrm{x} \quad$ Regional lymph nodes cannot be assessed

0 No regional lymph node metastasis

1 Regional lymph node metastasis

\section{$M$ - Distant metastasis}

$\mathrm{x} \quad$ Distant metastasis cannot be assessed

$0 \quad$ No distant metastasis

1 Distant metastasis

b Staging of Si-NENs

\begin{tabular}{|c|c|c|c|c|c|}
\hline \multirow{3}{*}{$\frac{\text { Stage }}{0}$} & & \multicolumn{3}{|l|}{ TNM } & \multirow{2}{*}{$\begin{array}{l}\text { Disease } \\
\text { localized }\end{array}$} \\
\hline & & Tis & No & M0 & \\
\hline & & \multicolumn{3}{|c|}{ (Stage 0: ENETS only) } & \\
\hline I & & T1 & N0 & M0 & \\
\hline \multirow[t]{2}{*}{ II } & $\mathrm{a}$ & $\mathrm{T} 2$ & N0 & M0 & \\
\hline & $\mathrm{b}$ & $\mathrm{T} 3$ & No & M0 & \\
\hline \multirow[t]{2}{*}{$\overline{\text { III }}$} & $\underline{\mathrm{a}}$ & $\mathrm{T} 4$ & N0 & M0 & \\
\hline & $\mathrm{b}$ & any $\mathrm{T}$ & N1 & M0 & regional \\
\hline$\overline{\mathrm{IV}}$ & & any $\mathrm{T}$ & any & M1 & distant \\
\hline
\end{tabular}

c Grading of Si-NENs

\begin{tabular}{lll}
\hline Grade & Ki-67 index (\%) & $\begin{array}{l}\text { Mitotic index } \\
(\text { mitoses/10 HPF) }\end{array}$ \\
\hline G1 & $\leq 2$ & $<2$ \\
G2 & $3-20$ & $2-20$ \\
G3 & $>20$ & $>20$ \\
\hline
\end{tabular}

\section{Pathology}

A pathological diagnosis is mandatory in all cases and usually obtained on ultrasonography-guided liver biopsy or surgical biopsy. A pathological diagnosis of jejunal-ileal tumors is achieved using hematoxylin-eosin staining and immunohistochemical staining with $\mathrm{CgA}$ and synaptophysin $[3,20,71,72]$. As opposed to serum levels of
$\mathrm{CgA}$, weaker $\mathrm{CgA}$ staining on immunohistochemistry may indicate a poorer prognosis [30, 73]. A determination of the mitotic index and a calculation of the Ki-67 index by immunohistochemistry are mandatory and prognostically relevant in jejuno-ileal NENs $[3,21]$. The tumors should be classified according to the WHO system [20] including TNM staging [3, 72] and Ki-67 grading $[3,20,72]$ (table 1). Immunohistochemical staining for somatostatin receptors 2 (SSR-2) has been suggested by several studies [74] to correlate with, or at least be indicative of, a therapeutic response to somatostatin analogue (SSA) treatment. However, currently it can only be considered optional, since methodological variations and current data do not show a completely conclusive pattern. Thus, SSA treatment may be initiated although SSR-2 staining may be weak or even absent on immunohistochemistry.

In patients with liver metastases from a NEN of unknown primary tumor localization, nuclear immunohistochemical positivity for cdx-2 and/or serotonin with negativity for TTF-1 and ISL-1 is supportive of intestinal especially jejuno-ileal origin [75]. Other markers such as E-cadherin, p53, p27, VEGF and others have not been established as yet for routine diagnostics, although they may play a role in the future [76-78].

A familial or genetic predisposition to Si-NEN has not been established; however, recent reports have shown some familial associations which strongly suggest that a genetic predisposition may exist in rare instances [7981]. Other changes such as allelic loss of chromosome 18q have been reported to indicate adverse prognosis, but currently they have no role outside of research studies $[82,83]$. There is no indication to perform germline or somatic DNA testing and genetic counseling in the absence of other tumors or a family history.

\section{Minimal Consensus Statement on Pathology}

Histopathology

Histology is always necessary to establish the diagnosis of a NEN. Cytology may be helpful, particularly in a metastatic setting. The minimal ancillary tests to support a histological diagnosis include immunohistochemistry for CgA, synaptophysin and, optionally, serotonin. The mitotic count in $10 \mathrm{HPF}\left(2 \mathrm{~mm}^{2}\right)$ evaluated in areas of highest mitotic density, the Ki-67 index (MIB1 antibody; percentage of 2,000 cells in areas of highest nuclear labeling) and TNM staging according to the UICC classification and ENETS guidelines should be reported. Immunohistochemistry for cdx-2, p53 and SSR-2 is optional. The histopathology report should allow for a correct classification according to the current WHO criteria. In the future, it should also provide information for a correct TNM classification and grading (table 1a-c). Figure 1 summarizes the diagnostic algorithm of Si-NEN. 


\begin{tabular}{|c|c|c|c|c|c|}
\hline Disease & Localized & Regional & \multicolumn{3}{|c|}{ Distant } \\
\hline Stage & I/II & III & \multicolumn{3}{|c|}{ IV } \\
\hline TNM & T1-3N0M0 & $\begin{array}{l}\text { T4N0M0 } \\
\text { T1-4N1M0 }\end{array}$ & & TxNxM1 & \\
\hline Surgical treatment & \multicolumn{2}{|c|}{ Radical resection } & $\begin{array}{l}\text { Radical resection } \\
\text { with curative intent }\end{array}$ & Palliative resection & No resection \\
\hline & \multicolumn{2}{|c|}{$\begin{array}{l}\text { Local radical open (or in selected pts) } \\
\text { laparoscopic resection* of } \\
\text { - } \quad \text { primary tumor(s)** } \\
\text { - lymph nodes (dissection along the } \\
\text { superior mesenteric root) }\end{array}$} & $\begin{array}{ll}\text { Local radical open } \\
\text { resection of } \\
\text { • } & \text { primary } \\
& \text { tumor(s) } \\
\cdot & \text { lymph nodes } \\
& \text { (dissection } \\
\text { along the } \\
\text { superior } \\
\text { mesenteric } \\
\text { root) } \\
\\
\text { in combination } \\
\text { with: } \\
\text {. mets (liver) }\end{array}$ & 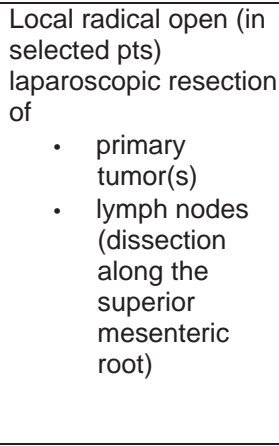 & $\begin{aligned} \text { Due to: } & \\
\cdot & \text { local } \\
& \text { inoperability } \\
\cdot & \text { comorbidity }\end{aligned}$ \\
\hline Aim & \multicolumn{2}{|c|}{ Free from tumor } & Free from tumor & $\begin{array}{l}\text { To avoid local } \\
\text { complications } \\
\text { (obstruction, } \\
\text { bleeding etc.) } \\
\text { To possibly } \\
\text { improve } \\
\text { prognosis* }\end{array}$ & \\
\hline
\end{tabular}

Fig. 2. Therapeutic algorithm for Si-NENs. Pts = Patients; mets = metastasis. ${ }^{*}$ For details, see the text. ${ }^{* *}$ Caution: multiple primaries.

\section{Curative Surgery}

Figure 2 summarizes a proposed therapeutic algorithm for Si-NENs.

\section{Resection of Localized and Regional Disease (Stage I-III)}

All patients with Si-NENs should be considered potential candidates for curative surgery of the primary tumor and regional lymph-node metastasis [76, 78-81, 83]. Patients should be evaluated in a multidisciplinary setting including an experienced visceral surgeon $[7,25,30,31$, 84-91]. Curative resection of the primary tumor and dissection of the locoregional lymph node metastasis along the superior mesenteric root and around the mesentery, aiming to preserve the vascular supply [92], improve the outcome in these patients resulting in excellent 5- and 10year survival rates of $100 \%$ in stage I and II patients and
$>95 \%$ and $>80 \%$, respectively, in stage III Si-NEN patients [21]. The review of a large number of surgical patients demonstrated that regional mesenteric lymphadenectomy in conjunction with the resection of the primary tumor is associated with improved survival of Si-NEN patients [93]

Any surgical procedure should follow the principles of oncological surgery in the small intestinal tract [84-91], but sometimes a concomitant right-sided hemicolectomy may be required if the tumor is located in the terminal ileum. Age, disease stage and complete resection were identified as independent prognostic factors for survival in Si-NEN patients. Localized and regionally restricted (Stage I-III) Si-NENs have an excellent prognosis after radical surgical treatment. The importance of achieving R0 resection is therefore emphasized $[94,95]$. To limit the extent of small intestinal resection, lymphatic mapping has been suggested to be helpful, but it is not a standardized procedure and therefore not generally recommended $[96,97]$. 
A minimally invasive approach can be considered, provided that oncological surgical standards can be achieved; however, patients with large mesenteric infiltration and multiple tumors are probably not optimal candidates for laparoscopic resection. The level of evidence for the role of laparoscopic surgery for Si-NEN is low. There is a lack of randomized trials. Only few singlecenter studies describe small numbers of patients after laparoscopic resection of primary Si-NENs [98]. Laparoscopic techniques are feasible and safe and are to be favored due to the general advantages of a laparoscopic surgical approach; however, the potential benefits of minimally invasive surgery have to be weighed against the risk of incomplete (i.e. noncurative) tumor resection (especially in the event of multiple small Si-NENs).

Postoperative malabsorption and/or bile-salt-induced diarrhea due to the resection of more or less extensive parts of the distal small intestine, and particularly the terminal ileum, may be observed and require either medical (e.g. cholestyramine) or nutritional therapy. However, postoperative mortality should be $<2 \%$ and significant morbidity $<20 \%[28,87]$.

\section{Concomitant Cholecystectomy}

Since cholelithiasis appears to be increased in NEN patients, particularly in those on SSA therapy, cholecystectomy has been recommended even for nonsymptomatic patients in the past [99]. However, prospective proof of this concept has never been produced, and there is an ongoing debate as to whether routine cholecystectomy is required or not $[100,101]$ because the increased incidence of cholelithiasis does not consistently lead to cholecystitis. It may therefore be individually decided by the surgeon, depending on technical and clinical aspects (e.g. the presence of cholelithiasis, previous episodes of cholecystitis or cholangitis, presumed cholecystitis-associated right upper abdominal pain, planned transarterial chemo-/embolization or selective internal radiotherapy and the intraoperative risk of cholecystectomy in an emergency situation). However, a prophylactic cholecystectomy should be performed at laparotomy if patients are planned to undergo treatment with SSAs [100].

\section{Minimal Consensus Statement on Curative Surgery}

Curative surgery is always recommended whenever feasible. Surgery of the primary should be performed as segmental resection with wide lymphadenectomy. In case of lymph node involvement around the superior mesenteric artery, high lymph node dissection is recommended. In cases with severe desmoplastic reaction around the artery, radical tumor resection may not be possible.

Cholecystectomy may be performed during the initial session as prophylaxis against the development of gallstones (frequent in patients that will require SSA treatment), although the benefit of cholecystectomy has never been prospectively proven. In emergency situations, cholecystectomy may therefore not be enforced.

Tumor multicentricity, which may occur in $20 \%$ of all cases, demonstrated by SRS, cross-sectional imaging, intraoperative palpation and/or endoscopy, does not change the indication for surgery. A minimally invasive (laparoscopic) approach may be considered, provided that oncological surgical standards can realistically be achieved; patients with large mesenteric infiltration and multiple tumors are not candidates for extended laparoscopic procedures.

The outcome of surgery may be worse in cases with distant metastases other than in the liver, as well as in cases with the socalled frozen mesenteric root and peritoneal carcinomatosis. Careful pre- and perioperative symptomatic control of any carcinoid syndrome can be achieved by medical treatment (s.c. or i.v. SSAs).

After curative surgery, there is no indication for specific medical treatment, and there is no proven role for neoadjuvant or adjuvant medical treatment in Si-NEN patients.

\section{Palliative Surgery in Distant Disease (Stage IV)}

\section{Palliative (Prophylactic) Resection of the Primary \\ Tumor in Metastatic Disease}

In cases with distant metastases, the decision of whether to resect the primary tumor or not is influenced by three considerations: (1) if a curative approach including the curative resection of the distant metastases (mostly liver metastases) [102] can still be reasonably achieved, then a primary tumor resection should be performed following oncological standards as outlined above [103]. (2) In symptomatic patients with symptoms due to small intestinal obstruction, (impeding) occlusion or tumor bleeding, the palliative resection of the primary tumor is obviously mandatory to prevent clinical deterioration or death. To avoid local vessel occlusion with ischemic bowel complications by intra-abdominal fibrosis, mesenteric lymph node metastases should also be removed as completely as possible. (3) If a curative approach seems no longer achievable, primary tumor resection may still improve the overall outcome and can therefore be considered [28, 104], although this has not been shown to be reproducible in all series [25]. However, these data are all influenced by their retrospective nature and a potential 'surgical' bias favoring resectable and thus less morbid patients. Thus, in the third setting, comorbidities should be carefully 
considered, probably best in an interdisciplinary setting to avoid unnecessary risks to the patient.

As shown recently, available data from six comparable clinical observational studies suggest a possible benefit of local resection of the primary Si-NEN and the regional metastasis in patients with unresectable liver metastases, but the studies included in the systematic review of the literature have several limitations, and the results should therefore be considered with caution [105].

The aspects of debulking surgery were discussed in the previous guidelines $[102,106]$.

\section{Minimal Consensus Statement on Palliative Resection in Stage IV}

Palliative resection for patients with endocrine tumors of the jejuno-ileum has the objective to make liver metastases the only persisting problem or to improve prognosis.

A resection of the small intestinal primary tumor should be attempted because the overall outcome is better in patients after primary tumor resection, although a direct causal relationship has not been proven to date; a multidisciplinary discussion is recommended for such a decision. Resection should also be considered in symptomatic patients and in patients in whom imaging (bowel dilatation, mesenteric fibrosis) suggests that obstruction will probably occur.

Patients suitable for palliative debulking procedures are those presumed to benefit from tumor reduction performed in accordance with given guidelines. Palliative surgery should mainly be done for symptomatic reasons or to facilitate other therapeutic modalities, i.e. medical and radionuclide treatment. The type of surgery should be individualized, no general approach can be recommended. If liver metastasis requires a minor resection, this can be done at the same procedure as the primary, otherwise it should be done at a second operation.

In the palliative setting, medical therapy is frequently required pre-, peri- and postoperatively. For further recommendations, please refer to the paper on metastasis [102].

\section{CHD (Hedinger Syndrome)}

CHD can be detected in 25-50\% of all patients with the carcinoid syndrome $[28,30,107-114]$. Recently, the current knowledge of its pathophysiology and treatment has been summarized by Grozinsky-Glasberg et al. [114]. $\mathrm{CHD}$ indicates a poor prognosis and is associated with clinical signs of right-sided heart failure, echocardiographic signs of right ventricular dilatation or tricuspid valve regurgitation depending on the duration of CHD. Prognosis has improved over the last 20 years from a 5 -year survival from $<30 \%$ in the 1980 s to now approximately $55 \%$. The most important reason for this improvement is successful cardiac surgery with valve replacement
$[108,109,111,115]$. CHD is characterized by plaque-like fibrous endocardial thickening that principally involves the right side of the heart, causing retraction and fixation of the leaflets of the tricuspid and pulmonary valves as well as diminished right ventricular function [115-118]. These changes are thought to be elicited by excess serotonin release (patients usually have very high levels of serotonin and/or urinary 5-HIAA levels) and co-secretion of other fibrogenic factors such as tachykinins, connective tissue growth factor, transforming growth factor- $\beta$ and/or substance $P[113,115,116]$.

Transthoracic echocardiography is the most important diagnostic modality $[107,110,111]$, although cardiac MRI [119] and other newer techniques such as tissue Doppler imaging [120] may play a role in the future. $\mathrm{Na}$ triuretic peptides such as brain natriuretic peptide and its precursors have also been shown to be quite sensitive indicators of early CHD and may be monitored regularly for early detection of CHD when available [120]. Screening for CHD should be performed on a regular basis, particularly prior to planned surgical procedures. If it develops, heart failure rather than metastatic disease may be the cause of death. Medical therapy for heart failure should be introduced when necessary. SSAs are mandatory and have shown improvement in cardiac reserve, although they may not prevent CHD progression, and cardiac surgery with valve replacement (bioprosthesis) should be considered for patients in whom control of hormonal symptoms and tumor growth has been achieved. Cardiac surgery should be performed before major liver surgery or liver embolization, while on the other hand early liver metastasis resection may slow the progression of CHD particularly in its earlier stages.

More recently, the coexistence of a patent foramen ovale (PFO) has been described together with CHD [121123], and it may increase the chance of left-sided heart lesions; its closure has also improved functional outcome in CHD patients. A PFO should therefore be ruled out in clinically progressing $\mathrm{CHD}$ and prior to cardiac surgery.

\section{Minimal Consensus Statement on CHD}

For patients with the carcinoid syndrome and CHD, transthoracic echocardiography should be performed annually; cardiac MRI may be helpful but its usefulness has not been proven as yet. SSAs are usually indicated in these patients presenting with often advanced carcinoid syndrome. For the timing of cardiac surgery with replacement of the tricuspid (and pulmonary) valves, brain natriuretic peptide measurements may be helpful, since they reflect the load on the right side of the heart. At cardiac imaging, a PFO should be ruled out; if present, its closure should be considered although only sparse data exist for this ap- 
proach. Decisions towards cardiologic intervention or cardiac surgery should be made on an individual basis in collaboration with an experienced cardiologist and cardiac surgeon.

\section{Follow-up}

A precise follow-up strategy is described in the ENETS standards of care [124]. Briefly, for patients having undergone surgery with a curative intent, the schedule for follow-up should be every 6-12 months, with the exception of G3 tumors, which should be followed every 3 months. Patients treated without curative intent should be followed initially at 3-6 months' intervals for G1/G2 neuroendocrine tumors, and this can be lengthened in very slowly progressive tumors. In very rare G3 neuroendocrine carcinomas, the intervals should not exceed 3 months. Minimal examination includes the measurement of CgA and 5-HIAA and a triphasic CT. SRI (SRS or PET/CT) should be performed in suspected recurrences before any therapeutic decisions are made, or even after curative resection with unknown NEN prior to surgery to rule out distant metastases. The follow-up should be life-long, considering that after 25 years only approximately $20 \%$ of all patients are free of disease $[30,125]$.

\section{Minimal Consensus Statement on Follow-up}

For guidelines regarding follow-up strategies, we recommend to follow the ENETS standards of care.

Please also refer to the consensus guideline updates for other gastroenteropancreatic neuroendocrine tumors [126-131, this issue].

\section{Appendix}

\section{All Other Vienna Consensus Conference Participants}

Anlauf, M. (Institut für Pathologie und Zytologie, St. Vincenz Krankenhaus, Limburg, Germany); Bartsch, D.K. (Department of Surgery, Philipps University, Marburg, Germany); Baudin, E. (Institut Gustave Roussy, Villejuif, France); Capdevila, J. (Insitute of Oncology, Vall d'Hebron University Hospital, Barcelona, Spain); Caplin, M. (Neuroendocrine Tumour Unit, Royal Free Hospital, London, UK); Cwikla, J.B. (Department of Radiology, Faculty of Medical Sciences, University of Warmia and Mazury, Olsztyn, Poland); De Herder, W.W. (Department of Internal Medicine, Division of Endocrinology, Erasmus Medical Center, Rotterdam, The Netherlands); Delle Fave, G. (Department of Digestive and Liver Disease, Ospedale Sant'Andrea, Rome, Italy); Eriksson, B. (Department of Endocrine Oncology, University Hospital, Uppsala, Sweden); Falconi, M. (Department of Surgery, San Raffaele Hospital, Università Vita e Salute, Milan, Italy); Ferolla, P. (NET Cen-

ter, Umbria Regional Cancer Network, Università degli Studi di Perugia, Perugia, Italy); Ferone, D. (Department of Endocrine and Metabolic Sciences, University of Genoa, Genoa, Italy); GarciaCarbonero, R. (Medical Oncology Department, Hospital Universitario Doce de Octubre, Madrid, Spain); Ito, T. (Pancreatic Diseases Branch, Kyushu University Hospital, Higashi-ku, Fukuoka, Japan); Jensen, R.T. (Digestive Diseases Branch, NIH, Bethesda, Md., USA); Kaltsas, G. (Department of Pathophysiology, Division of Endocrinology, National University of Athens, Athens, Greece); Klöppel, G. (Institute of Pathology, Technische Universität München, Munich, Germany); Kos-Kudla, B. (Department of Endocrinology, Medical University of Silesia, Katowice, Poland); Kwekkeboom, D. (Department of Internal Medicine, Division of Nuclear Medicine, Erasmus Medical Center, Rotterdam, The Netherlands); Pascher, A. (Department of Visceral and Transplant Surgery, Campus Virchow Klinikum, Charité Universitätsmedizin Berlin, Berlin, Germany); Ramage, J.K. (Gastroenterology Department, Hampshire Hospitals NHS Trust, Hampshire, UK); Raymond, E. (Oncologie Médicale, Hôpitaux Universitaires Paris Nord Val de Seine, Paris, France); Rindi, G. (Institute of Anatomic Pathology, Policlinico A. Gemelli, Università Cattolica del Sacro Cuore, Rome, Italy); Ruszniewski, P. (Department of Gastroenterology, Beaujon Hospital, Clichy, France); Sedlackova, E. (Department of Oncology, First Faculty of Medicine and General Teaching Hospital, Prague, Czech Republic); Sorbye, H. (Department of Oncology, Haukeland University Hospital, Bergen, Norway); Sundin, A. (Department of Radiology, Section for Molecular Imaging, University Hospital, Uppsala, Sweden); Taal, B. (Netherlands Cancer Centre, Lijnden, The Netherlands); Weber, W. (Department of Radiology, Memorial Sloan Kettering Cancer Center, New York, N.Y., USA); Wiedenmann, B. (Department of Hepatology and Gastroenterology, Campus Virchow Klinikum, Charité Universitätsmedizin Berlin, Berlin, Germany); Zheng-Pei, Z. (Department of Endocrinology, Peking Union Medical College Hospital, Beijing, China).

References

Pape UF, Perren A, Niederle B, Gross D, Gress T, Costa F, Arnold R, Denecke T, Plockinger U, Salazar R, Grossman A: ENETS Consensus Guidelines for the management of patients with neuroendocrine neoplasms from the jejuno-ileum and the appendix including goblet cell carcinomas. Neuroendocrinology 2012;95:135-156.

2 Niederle MB, Hackl M, Kaserer K, Niederle B Gastroenteropancreatic neuroendocrine tumours: the current incidence and staging based on the WHO and European Neuroendocrine Tumour Society classification: an analysis based on prospectively collected parameters. Endocr Relat Cancer 2010;17:909918.

3 Rindi G, Kloppel G, Couvelard A, Komminoth P, Korner M, Lopes JM, McNicol AM, Nilsson O, Perren A, Scarpa A, Scoazec JY, Wiedenmann B: TNM staging of midgut and hindgut (neuro) endocrine tumors: a consensus proposal including a grading system. Virchows Arch 2007;451:757-762. 
4 Modlin IM, Oberg K, Chung DC, Jensen RT, de Herder WW, Thakker RV, Caplin M, Delle Fave G, Kaltsas GA, Krenning EP, Moss SF, Nilsson O, Rindi G, Salazar R, Ruszniewski P, Sundin A: Gastroenteropancreatic neuroendocrine tumours. Lancet Oncol 2008;9: 61-72.

5 Scherubl H, Streller B, Stabenow R, Herbst H, Hopfner M, Schwertner C, Steinberg J, Eick J, Ring W, Tiwari K, Zappe SM: Clinically detected gastroenteropancreatic neuroendocrine tumors are on the rise: epidemiological changes in Germany. World J Gastroenterol 2013;19:9012-9019.

6 Yao JC, Hassan M, Phan A, Dagohoy C, Leary C, Mares JE, Abdalla EK, Fleming JB, Vauthey JN, Rashid A, Evans DB: One hundred years after 'carcinoid': epidemiology of and prognostic factors for neuroendocrine tumors in 35,825 cases in the United States. J Clin Oncol 2008;26:3063-3072.

7 Niederle MB, Niederle B: Diagnosis and treatment of gastroenteropancreatic neuroendocrine tumors: current data on a prospectively collected, retrospectively analyzed clinical multicenter investigation. Oncologist 2011; 16:602-613.

8 Eriksson B, Kloppel G, Krenning E, Ahlman $\mathrm{H}$, Plockinger U, Wiedenmann B, Arnold R, Auernhammer C, Korner M, Rindi G, Wildi $S$ : Consensus guidelines for the management of patients with digestive neuroendocrine tumors - well-differentiated jejunal-ileal tumor/ carcinoma. Neuroendocrinology 2008;87:819.

9 Plockinger U, Rindi G, Arnold R, Eriksson B, Krenning EP, de Herder WW, Goede A, Caplin M, Oberg K, Reubi JC, Nilsson O, Delle Fave G, Ruszniewski P, Ahlman H, Wiedenmann B: Guidelines for the diagnosis and treatment of neuroendocrine gastrointestinal tumours. A consensus statement on behalf of the European Neuroendocrine Tumour Society (ENETS). Neuroendocrinology 2004;80: 394-424.

10 Oberndorfer S: Karzinoide Tumoren des Dünndarms. Frankf Z Pathol 1907;1:426432.

11 Ellis L, Shale MJ, Coleman MP: Carcinoid tumors of the gastrointestinal tract: trends in incidence in England since 1971. Am J Gastroenterol 2010;105:2563-2569.

12 Ito T, Sasano H, Tanaka M, Osamura RY, Sasaki I, Kimura W, Takano K, Obara T, Ishibashi M, Nakao K, Doi R, Shimatsu A, Nishida T, Komoto I, Hirata Y, Nakamura K, Igarashi $\mathrm{H}$, Jensen $\mathrm{RT}$, Wiedenmann $\mathrm{B}$, Imamura M: Epidemiological study of gastroenteropancreatic neuroendocrine tumors in Japan. J Gastroenterol 2010;45:234-243.

13 Hauso O, Gustafsson BI, Kidd M, Waldum HL, Drozdov I, Chan AK, Modlin IM: Neuroendocrine tumor epidemiology: contrasting Norway and North America. Cancer 2008; 113:2655-2664.
14 Landerholm K, Falkmer S, Jarhult J: Epidemiology of small bowel carcinoids in a defined population. World J Surg 2010;34:1500-1505.

15 Garcia-Carbonero R, Capdevila J, CrespoHerrero G, et al: Incidence, patterns of care and prognostic factors for outcome of gastroenteropancreatic neuroendocrine tumors (GEP-NETs): results from the National Cancer Registry of Spain (RGETNE). Ann Oncol 2010;21:1794-1803.

16 Lepage C, Bouvier AM, Manfredi S, Dancourt $\mathrm{V}$, Faivre J: Incidence and management of primary malignant small bowel cancers: a well-defined French population study. Am J Gastroenterol 2006;101:2826-2832.

17 Ploeckinger U, Kloeppel G, Wiedenmann B, Lohmann R: The German NET-registry: an audit on the diagnosis and therapy of neuroendocrine tumors. Neuroendocrinology 2009;90:349-363.

18 Bergestuen DS, Aabakken L, Holm K, Vatn M, Thiis-Evensen E: Small intestinal neuroendocrine tumors: prognostic factors and survival. Scand J Gastroenterol 2009;44: 1084-1091.

19 Berge T, Linell F: Carcinoid tumours. Frequency in a defined population during a 12year period. Acta Pathol Microbiol Scand A 1976;84:322-330.

20 Klimstra DS, Arnold R, Capella C, et al: WHO Classification of Tumours of the Digestive System. Lyon, IACR, 2010.

21 Jann H, Roll S, Couvelard A, Hentic O, Pavel M, Muller-Nordhorn J, Koch M, Rocken C, Rindi G, Ruszniewski P, Wiedenmann B, Pape UF: Neuroendocrine tumors of midgut and hindgut origin: tumor-node-metastasis classification determines clinical outcome. Cancer 2011;117:3332-3341.

22 Boudreaux JP, Klimstra DS, Hassan MM, Woltering EA, Jensen RT, Goldsmith SJ, Nutting C, Bushnell DL, Caplin ME, Yao JC: The NANETS consensus guideline for the diagnosis and management of neuroendocrine tumors: well-differentiated neuroendocrine tumors of the Jejunum, Ileum, Appendix, and Cecum. Pancreas 2010;39:753-766.

23 Quaedvlieg PF, Visser O, Lamers CB, Janssen-Heijen ML, Taal BG: Epidemiology and survival in patients with carcinoid disease in The Netherlands. An epidemiological study with 2391 patients. Ann Oncol 2001;12:12951300.

24 Perez EA, Koniaris LG, Snell SE, Gutierrez JC, Sumner WE 3rd, Lee DJ, Hodgson NC, Livingstone AS, Franceschi D: 7,201 carcinoids: increasing incidence overall and disproportionate mortality in the elderly. World J Surg 2007;31:1022-1030.

25 Strosberg J, Gardner N, Kvols L: Survival and prognostic factor analysis of 146 metastatic neuroendocrine tumors of the mid-gut. Neuroendocrinology 2009;89:471-476.
26 Norlen O, Stalberg P, Oberg K, Eriksson J, Hedberg J, Hessman O, Janson ET, Hellman P, Akerstrom G: Long-term results of surgery for small intestinal neuroendocrine tumors at a tertiary referral center. World J Surg 2012; 36:1419-1431.

27 Aggarwal G, Obideen K, Wehbi M: Carcinoid tumors: what should increase our suspicion? Cleve Clin J Med 2008;75:849-855.

28 Ahmed A, Turner G, King B, Jones L, Culliford D, McCance D, Ardill J, Johnston BT, Poston G, Rees M, Buxton-Thomas M, Caplin M, Ramage JK: Midgut neuroendocrine tumours with liver metastases: results of the UKINETS study. Endocr Relat Cancer 2009; 16:885-894.

29 Helland SK, Prosch AM, Viste A: Carcinoid tumours in the gastrointestinal tract - a population-based study from Western Norway. Scand J Surg 2006;95:158-161.

30 Pape UF, Berndt U, Muller-Nordhorn J, Bohmig M, Roll S, Koch M, Willich SN, Wiedenmann B: Prognostic factors of long-term outcome in gastroenteropancreatic neuroendocrine tumours. Endocr Relat Cancer 2008; 15:1083-1097.

31 Pape UF, Bohmig M, Berndt U, Tiling N, Wiedenmann B, Plockinger U: Survival and clinical outcome of patients with neuroendocrine tumors of the gastroenteropancreatic tract in a German referral center. Ann NY Acad Sci 2004;1014:222-233.

32 Druce MR, Bharwani N, Akker SA, Drake WM, Rockall A, Grossman AB: Intra-abdominal fibrosis in a recent cohort of patients with neuroendocrine ('carcinoid') tumours of the small bowel. QJM 2010;103:177-185.

33 Castillo JG, Filsoufi F, Adams DH, Raikhelkar J, Zaku B, Fischer GW: Management of patients undergoing multivalvular surgery for carcinoid heart disease: the role of the anaesthetist. Br J Anaesth 2008;101:618-626.

34 Kaltsas G, Rockall A, Papadogias D, Reznek $\mathrm{R}$, Grossman AB: Recent advances in radiological and radionuclide imaging and therapy of neuroendocrine tumours. Eur J Endocrinol 2004;151:15-27.

35 Ricke J, Klose KJ, Mignon M, Oberg K, Wiedenmann B: Standardisation of imaging in neuroendocrine tumours: results of a European delphi process. Eur J Radiol 2001;37:817.

36 Kamaoui I, De-Luca V, Ficarelli S, Mennesson N, Lombard-Bohas C, Pilleul F: Value of CT enteroclysis in suspected small-bowel carcinoid tumors. AJR Am J Roentgenol 2010; 194:629-633.

37 Masselli G, Polettini E, Casciani E, Bertini L, Vecchioli A, Gualdi G: Small-bowel neoplasms: prospective evaluation of MR enteroclysis. Radiology 2009;251:743-750.

38 Dorffel Y, Wermke W: Neuroendocrine tumors: characterization with contrast-enhanced ultrasonography. Ultraschall Med 2008;29:506-514. 
39 Bailey AA, Debinski HS, Appleyard MN, Remedios ML, Hooper JE, Walsh AJ, Selby WS: Diagnosis and outcome of small bowel tumors found by capsule endoscopy: a threecenter Australian experience. Am J Gastroenterol 2006;101:2237-2243.

40 Bellutti M, Fry LC, Schmitt J, Seemann M, Klose S, Malfertheiner P, Monkemuller K: Detection of neuroendocrine tumors of the small bowel by double balloon enteroscopy. Dig Dis Sci 2009;54:1050-1058.

41 Frilling A, Smith G, Clift AK, Martin J: Capsule endoscopy to detect primary tumour site in metastatic neuroendocrine tumours. Dig Liver Dis 2014;46:1038-1042.

42 Ambrosini V, Tomassetti P, Castellucci P, Campana D, Montini G, Rubello D, Nanni C, Rizzello A, Franchi R, Fanti S: Comparison between 68Ga-DOTA-NOC and 18F-DOPA PET for the detection of gastro-entero-pancreatic and lung neuro-endocrine tumours. Eur J Nucl Med Mol Imaging 2008;35:14311438.

43 Buchmann I, Henze M, Engelbrecht S, Eisenhut M, Runz A, Schafer M, Schilling T, Haufe S, Herrmann T, Haberkorn U: Comparison of 68Ga-DOTATOC PET and 111In-DTPAOC (Octreoscan) SPECT in patients with neuroendocrine tumours. Eur J Nucl Med Mol Imaging 2007;34:1617-1626.

44 Ezziddin S, Logvinski T, Yong-Hing C, Ahmadzadehfar $\mathrm{H}$, Fischer HP, Palmedo $\mathrm{H}$, Bucerius J, Reinhardt MJ, Biersack HJ: Factors predicting tracer uptake in somatostatin receptor and MIBG scintigraphy of metastatic gastroenteropancreatic neuroendocrine tumors. J Nucl Med 2006;47:223-233.

45 Gabriel M, Decristoforo C, Kendler D, Dobrozemsky G, Heute D, Uprimny C, Kovacs P, Von Guggenberg E, Bale R, Virgolini IJ: 68Ga-DOTA-Tyr3-octreotide PET in neuroendocrine tumors: comparison with somatostatin receptor scintigraphy and CT. J Nucl Med 2007;48:508-518.

46 Haug A, Auernhammer CJ, Wangler B, Tiling R, Schmidt G, Goke B, Bartenstein P, Popperl $\mathrm{G}$ : Intraindividual comparison of $68 \mathrm{Ga}$ DOTA-TATE and 18F-DOPA PET in patients with well-differentiated metastatic neuroendocrine tumours. Eur J Nucl Med Mol Imaging 2009;36:765-770.

47 Koopmans KP, Neels OC, Kema IP, Elsinga $\mathrm{PH}$, Sluiter WJ, Vanghillewe K, Brouwers AH, Jager PL, de Vries EG: Improved staging of patients with carcinoid and islet cell tumors with $18 \mathrm{~F}$-dihydroxy-phenyl-alanine and 11C5-hydroxy-tryptophan positron emission tomography. J Clin Oncol 2008;26:1489-1495.

48 Montravers F, Kerrou K, Nataf V, Huchet V, Lotz JP, Ruszniewski P, Rougier P, Duron F, Bouchard P, Grange JD, Houry S, Talbot JN: Impact of fluorodihydroxyphenylalanine$18 \mathrm{~F}$ positron emission tomography on management of adult patients with documented or occult digestive endocrine tumors. J Clin Endocrinol Metab 2009;94:1295-1301.
49 Orlefors H, Sundin A, Garske U, Juhlin C, Oberg K, Skogseid B, Langstrom B, Bergstrom M, Eriksson B: Whole-body (11)C5-hydroxytryptophan positron emission tomography as a universal imaging technique for neuroendocrine tumors: comparison with somatostatin receptor scintigraphy and computed tomography. J Clin Endocrinol Metab 2005;90:3392-3400.

50 Prasad V, Ambrosini V, Hommann M, Hoersch D, Fanti S, Baum RP: Detection of unknown primary neuroendocrine tumours (CUP-NET) using (68)Ga-DOTA-NOC receptor PET/CT. Eur J Nucl Med Mol Imaging 2010;37:67-77.

51 Prasad V, Baum RP: Biodistribution of the Ga-68 labeled somatostatin analogue DOTANOC in patients with neuroendocrine tumors: characterization of uptake in normal organs and tumor lesions. Q J Nucl Med Mol Imaging 2010;54:61-67.

52 Ruf J, Heuck F, Schiefer J, Denecke T, Elgeti F, Pascher A, Pavel M, Stelter L, Kropf S, Wiedenmann B, Amthauer H: Impact of multiphase $68 \mathrm{Ga}-\mathrm{DOTATOC}$-PET/CT on therapy management in patients with neuroendocrine tumors. Neuroendocrinology 2010;91:101109.

53 Ruf J, Schiefer J, Furth C, Kosiek O, Kropf S, Heuck F, Denecke T, Pavel M, Pascher A, Wiedenmann B, Amthauer H: 68Ga-DOTATOC PET/CT of neuroendocrine tumors: spotlight on the CT phases of a triple-phase protocol. J Nucl Med 2011;52:697-704.

54 Ruf J, Steffen I, Mehl S, Rosner C, Denecke T, Pape UF, Plotkin M, Amthauer H: Influence of attenuation correction by integrated lowdose CT on somatostatin receptor SPECT. Nucl Med Commun 2007;28:782-788.

55 Koopmans KP, de Vries EG, Kema IP, Elsinga PH, Neels OC, Sluiter WJ, van der HorstSchrivers AN, Jager PL: Staging of carcinoid tumours with $18 \mathrm{~F}-\mathrm{DOPA}$ PET: a prospective, diagnostic accuracy study. Lancet Oncol 2006;7:728-734.

56 Schreiter NF, Bartels AM, Froeling V, Steffen I, Pape UF, Beck A, Hamm B, Brenner W, Rottgen R: Searching for primaries in patients with neuroendocrine tumors (NET) of unknown primary and clinically suspected NET: evaluation of Ga-68 DOTATOC PET/CT and In-111 DTPA octreotide SPECT/CT. Radiol Oncol 2014;48:339-347.

57 Meijer WG, van der Veer E, Jager PL, van der Jagt EJ, Piers BA, Kema IP, de Vries EG, Willemse PH: Bone metastases in carcinoid tumors: clinical features, imaging characteristics, and markers of bone metabolism. J Nucl Med 2003;44:184-191.

58 Ardill JE, Erikkson B: The importance of the measurement of circulating markers in patients with neuroendocrine tumours of the pancreas and gut. Endocr Relat Cancer 2003; 10:459-462.

59 Eriksson B, Oberg K: Peptide hormones as tumor markers in neuroendocrine gastrointestinal tumors. Acta Oncol 1991;30:477-483.
60 Feldman JM, O'Dorisio TM: Role of neuropeptides and serotonin in the diagnosis of carcinoid tumors. Am J Med 1986;81:41-48.

61 Arnold R, Wilke A, Rinke A, Mayer C, Kann PH, Klose KJ, Scherag A, Hahmann M, Muller $\mathrm{HH}$, Barth P: Plasma chromogranin A as marker for survival in patients with metastatic endocrine gastroenteropancreatic tumors. Clin Gastroenterol Hepatol 2008;6:820-827.

62 Korse CM, Bonfrer JM, Aaronson NK, Hart AA, Taal BG: Chromogranin A as an alternative to 5-hydroxyindoleacetic acid in the evaluation of symptoms during treatment of patients with neuroendocrine tumors. Neuroendocrinology 2009;89:296-301.

63 Peracchi M, Gebbia C, Basilisco G, Quatrini M, Tarantino C, Vescarelli C, Massironi S, Conte D: Plasma chromogranin A in patients with autoimmune chronic atrophic gastritis, enterochromaffin-like cell lesions and gastric carcinoids. Eur J Endocrinol 2005;152:443448.

64 Giusti M, Sidoti M, Augeri C, Rabitti C, Minuto F: Effect of short-term treatment with low dosages of the proton-pump inhibitor omeprazole on serum chromogranin A levels in man. Eur J Endocrinol 2004;150:299-303.

65 Massironi S, Fraquelli M, Paggi S, Sangiovanni A, Conte D, Sciola V, Ciafardini C, Colombo M, Peracchi M: Chromogranin A levels in chronic liver disease and hepatocellular carcinoma. Dig Liver Dis 2009;41:31-35.

66 Spadaro A, Ajello A, Morace C, Zirilli A, D'Arrigo G, Luigiano C, Martino F, Bene A, Migliorato D, Turiano S, Ferrau O, Freni MA: Serum chromogranin-A in hepatocellular carcinoma: diagnostic utility and limits. World J Gastroenterol 2005;11:1987-1990.

67 Welin S, Stridsberg M, Cunningham J, Granberg D, Skogseid B, Oberg K, Eriksson B, Janson ET: Elevated plasma chromogranin A is the first indication of recurrence in radically operated midgut carcinoid tumors. Neuroendocrinology 2009;89:302-307.

68 Kema IP, Meijer WG, Meiborg G, Ooms B, Willemse PH, de Vries EG: Profiling of tryptophan-related plasma indoles in patients with carcinoid tumors by automated, on-line, solid-phase extraction and HPLC with fluorescence detection. Clin Chem 2001;47:18111820.

69 Meijer WG, Kema IP, Volmer M, Willemse $\mathrm{PH}$, de Vries EG: Discriminating capacity of indole markers in the diagnosis of carcinoid tumors. Clin Chem 2000;46:1588-1596.

70 O’Toole D, Grossman A, Gross D, Delle Fave G, Barkmanova J, O'Connor J, Pape UF, Plockinger U: ENETS consensus guidelines for the standards of care in neuroendocrine tumors: biochemical markers. Neuroendocrinology 2009;90:194-202.

71 Hamilton S: Tumours of the Digestive System. Pathology and Genetics. WHO Classification of Tumours. Lyon, ARC, 2000.

72 Sobin LH, Gospodarowicz MK, Wittekind C: TNM Classification of Malignant Tumours. Oxford, Wiley-Blackwell, 2009. 
73 Welin S, Sorbye H, Sebjornsen S, Knappskog S, Busch C, Oberg K: Clinical effect of temozolomide-based chemotherapy in poorly differentiated endocrine carcinoma after progression on first-line chemotherapy. Cancer 2011;117:4617-4622.

74 Miederer M, Seidl S, Buck A, Scheidhauer K, Wester HJ, Schwaiger M, Perren A: Correlation of immunohistopathological expression of somatostatin receptor 2 with standardised uptake values in 68Ga-DOTATOC PET/CT. Eur J Nucl Med Mol Imaging 2009;36:48-52.

75 Schmitt AM, Riniker F, Anlauf M, Schmid S, Soltermann A, Moch H, Heitz PU, Kloppel G, Komminoth P, Perren A: Islet 1 (Isl1) expression is a reliable marker for pancreatic endocrine tumors and their metastases. Am J Surg Pathol 2008;32:420-425.

76 Besig S, Voland P, Baur DM, Perren A, Prinz C: Vascular endothelial growth factors, angiogenesis, and survival in human ileal enterochromaffin cell carcinoids. Neuroendocrinology 2009;90:402-415.

77 Grabowski P, Schrader J, Wagner J, Horsch D, Arnold R, Arnold CN, Georgieva I, Stein H, Zeitz M, Daniel PT, Sturm I: Loss of nuclear p27 expression and its prognostic role in relation to cyclin $\mathrm{E}$ and p53 mutation in gastroenteropancreatic neuroendocrine tumors. Clin Cancer Res 2008;14:7378-7384

78 Voland P, Besig S, Rad R, Braun T, Baur DM, Perren A, Langer R, Hofler H, Prinz C: Correlation of matrix metalloproteinases and tissue inhibitors of matrix metalloproteinase expression in ileal carcinoids, lymph nodes and liver metastasis with prognosis and survival. Neuroendocrinology 2009;89:66-78.

79 Hassan MM, Phan A, Li D, Dagohoy CG Leary C, Yao JC: Family history of cancer and associated risk of developing neuroendocrine tumors: a case-control study. Cancer Epidemiol Biomarkers Prev 2008;17:959-965.

80 Hemminki K, Li X: Familial carcinoid tumors and subsequent cancers: a nation-wide epidemiologic study from Sweden. Int J Cancer 2001;94:444-448.

81 Jarhult J, Landerholm K, Falkmer S, Nordenskjold M, Sundler F, Wierup N: First report on metastasizing small bowel carcinoids in first-degree relatives in three generations. Neuroendocrinology 2010;91:318-323.

82 Stancu M, Wu TT, Wallace C, Houlihan PS, Hamilton SR, Rashid A: Genetic alterations in goblet cell carcinoids of the vermiform appendix and comparison with gastrointestinal carcinoid tumors. Mod Pathol 2003;16:11891198.

83 Tonnies H, Toliat MR, Ramel C, Pape UF, Neitzel H, Berger W, Wiedenmann B: Analysis of sporadic neuroendocrine tumours of the enteropancreatic system by comparative genomic hybridisation. Gut 2001;48:536-541.

84 Ahlman H, Wangberg B, Jansson S, Friman S, Olausson M, Tylen U, Nilsson O: Interventional treatment of gastrointestinal neuroendocrine tumours. Digestion 2000;62(suppl 1): 59-68.
85 Akerstrom G, Makridis C, Johansson H: Abdominal surgery in patients with midgut carcinoid tumors. Acta Oncol 1991;30:547-553.

86 Goede AC, Winslet MC: Surgery for carcinoid tumours of the lower gastrointestinal tract. Colorectal Dis 2003;5:123-128.

87 Han SL, Cheng J, Zhou HZ, Guo SC, Jia ZR, Wang PF: Surgically treated primary malignant tumor of small bowel: a clinical analysis. World J Gastroenterol 2010;16:1527-1532.

88 Makridis C, Oberg K, Juhlin C, Rastad J, Johansson H, Lorelius LE, Akerstrom G: Surgical treatment of mid-gut carcinoid tumors. World J Surg 1990;14:377-383; discussion 384-375.

89 Norton JA: Surgical management of carcinoid tumors: role of debulking and surgery for patients with advanced disease. Digestion 1994; 55(suppl 3):98-103.

90 Rothmund M, Kisker O: Surgical treatment of carcinoid tumors of the small bowel, appendix, colon and rectum. Digestion 1994; 55(suppl 3):86-91.

91 Sutton R, Doran HE, Williams EM, Vora J, Vinjamuri S, Evans J, Campbell F, Raraty MG, Ghaneh P, Hartley M, Poston GJ, Neoptolemos JP: Surgery for midgut carcinoid. Endocr Relat Cancer 2003;10:469-481.

92 Ohrvall U, Eriksson B, Juhlin C, Karacagil S, Rastad J, Hellman P, Akerstrom G: Method for dissection of mesenteric metastases in mid-gut carcinoid tumors. World J Surg 2000; 24:1402-1408.

93 Landry CS, Lin HY, Phan A, Charnsangavej C, Abdalla EK, Aloia T, Nicolas Vauthey J, Katz MH, Yao JC, Fleming JB: Resection of at-risk mesenteric lymph nodes is associated with improved survival in patients with small bowel neuroendocrine tumors. World J Surg 2013;37:1695-1700.

94 Habbe N, Fendrich V, Heverhagen A, Ramaswamy A, Bartsch DK: Outcome of surgery for ileojejunal neuroendocrine tumors. Surg Today 2013;43:1168-1174.

95 Landerholm K, Zar N, Andersson RE, Falkmer SE, Jarhult J: Survival and prognostic factors in patients with small bowel carcinoid tumour. Br J Surg 2011;98:1617-1624.

96 Hellman P, Lundstrom T, Ohrvall U, Eriksson B, Skogseid B, Oberg K, Tiensuu Janson E, Akerstrom G: Effect of surgery on the outcome of midgut carcinoid disease with lymph node and liver metastases. World J Surg 2002; 26:991-997.

97 Wang YZ, Carrasquillo JP, McCord E, Vidrine R, Lobo ML, Zamin SA, Boudreaux $\mathrm{P}$, Woltering E: Reappraisal of lymphatic mapping for midgut neuroendocrine patients undergoing cytoreductive surgery. Surgery 2014;156:1498-1502; discussion 1502-1503.

98 Shamiyeh A, Gabriel M: Laparoscopic resection of gastrointestinal neuroendocrine tumors with special contribution of radionuclide imaging. World J Gastroenterol 2014;20: 15608-15615.
99 Eriksson J, Stalberg P, Nilsson A, Krause J, Lundberg C, Skogseid B, Granberg D, Eriksson B, Akerstrom G, Hellman P: Surgery and radiofrequency ablation for treatment of liver metastases from midgut and foregut carcinoids and endocrine pancreatic tumors. World J Surg 2008;32:930-938.

100 Norlen O, Hessman O, Stalberg P, Akerstrom G, Hellman P: Prophylactic cholecystectomy in midgut carcinoid patients. World J Surg 2010;34:1361-1367.

101 Toumpanakis C, Garland J, Marelli L, Srirajaskanthan R, Soh J, Davies P, Buscombe J, Caplin ME: Long-term results of patients with malignant carcinoid syndrome receiving octreotide LAR. Aliment Pharmacol Ther 2009;30:733-740.

102 Pavel M, Baudin E, Couvelard A, et al ENETS consensus guidelines for the management of patients with liver and other distant metastases from neuroendocrine neoplasms of foregut, midgut, hindgut and unknown primary. Neuroendocrinology 2012; 95:157-176.

103 Schindl M, Kaczirek K, Passler C, Kaserer K, Prager G, Scheuba C, Raderer M, Niederle B: Treatment of small intestinal neuroendocrine tumors: is an extended multimodal approach justified? World J Surg 2002;26:976984.

104 Givi B, Pommier SJ, Thompson AK, Diggs BS, Pommier RF: Operative resection of primary carcinoid neoplasms in patients with liver metastases yields significantly better survival. Surgery 2006;140:891-897; discussion 897-898

105 Capurso G, Rinzivillo M, Bettini R, Boninsegna L, Delle Fave G, Falconi M: Systematic review of resection of primary midgut carcinoid tumour in patients with unresectable liver metastases. Br J Surg 2012;99: 1480-1486.

106 Steinmuller T, Kianmanesh R, Falconi M, Scarpa A, Taal B, Kwekkeboom DJ, Lopes JM, Perren A, Nikou G, Yao J, Delle Fave GF, O'Toole D: Consensus guidelines for the management of patients with liver metastases from digestive (neuro)endocrine tumors: foregut, midgut, hindgut, and unknown primary. Neuroendocrinology 2008;87:47-62.

107 Bhattacharyya S, Davar J, Dreyfus G, Caplin ME: Carcinoid heart disease. Circulation 2007;116:2860-2865.

108 Castillo JG, Filsoufi F, Rahmanian PB, Anyanwu A, Zacks JS, Warner RR, Adams $\mathrm{DH}$ : Early and late results of valvular surgery for carcinoid heart disease. J Am Coll Cardiol 2008;51:1507-1509.

109 Mansencal N, Mitry E, Bachet JB, Rougier P Dubourg O: Echocardiographic follow-up of treated patients with carcinoid syndrome. Am J Cardiol 2010;105:1588-1591.

110 Moller JE, Connolly HM, Rubin J, Seward JB, Modesto K, Pellikka PA: Factors associated with progression of carcinoid heart disease. N Engl J Med 2003;348:1005-1015. 
111 Moller JE, Pellikka PA, Bernheim AM, Schaff HV, Rubin J, Connolly HM: Prognosis of carcinoid heart disease: analysis of 200 cases over two decades. Circulation 2005; 112:3320-3327.

112 Norheim I, Oberg K, Theodorsson-Norheim E, Lindgren PG, Lundqvist G, Magnusson A, Wide L, Wilander E: Malignant carcinoid tumors. An analysis of $103 \mathrm{pa}$ tients with regard to tumor localization, hormone production, and survival. Ann Surg 1987;206:115-125.

113 Zuetenhorst JM, Bonfrer JM, Korse CM, Bakker R, van Tinteren H, Taal BG: Carcinoid heart disease: the role of urinary 5 -hydroxyindoleacetic acid excretion and plasma levels of atrial natriuretic peptide, transforming growth factor-beta and fibroblast growth factor. Cancer 2003;97:1609-1615.

114 Grozinsky-Glasberg S, Grossman AB, Gross DJ: Carcinoid heart disease: from pathophysiology to treatment - 'Something in the way it moves'. Neuroendocrinology 2015; 101:263-273.

115 Bhattacharyya S, Raja SG, Toumpanakis C, Caplin ME, Dreyfus GD, Davar J: Outcomes, risks and complications of cardiac surgery for carcinoid heart disease. Eur J Cardiothorac Surg 2011;40:168-172.

116 Druce M, Rockall A, Grossman AB: Fibrosis and carcinoid syndrome: from causation to future therapy. Nat Rev Endocrinol 2009;5: 276-283.

117 Jacobsen MB, Nitter-Hauge S, Bryde PE, Hanssen LE: Cardiac manifestations in midgut carcinoid disease. Eur Heart J 1995; 16: 263-268.

118 Bhattacharyya S, Toumpanakis C, Chilkunda D, Caplin ME, Davar J: Risk factors for the development and progression of carcinoid heart disease. Am J Cardiol 2011;107: 1221-1226.

119 Sandmann H, Pakkal M, Steeds R: Cardiovascular magnetic resonance imaging in the assessment of carcinoid heart disease. Clin Radiol 2009;64:761-766.
120 Mansencal N, McKenna WJ, Mitry E, Beauchet A, Pellerin D, Rougier P, Dubourg O: Comparison of prognostic value of tissue Doppler imaging in carcinoid heart disease versus the value in patients with the carcinoid syndrome but without carcinoid heart disease. Am J Cardiol 2010; 105:527-531.

121 Zuetenhorst JM, Korse CM, Bonfrer JM, Bakker RH, Taal BG: Role of natriuretic peptides in the diagnosis and treatment of patients with carcinoid heart disease. Br J Cancer 2004;90:2073-2079.

122 Mansencal N, Mitry E, Forissier JF, Martin F, Redheuil A, Lepere C, Farcot JC, Joseph T, Lacombe P, Rougier P, Dubourg O: Assessment of patent foramen ovale in carcinoid heart disease. Am Heart J 2006;151:1129 e1121-e1126.

123 Mansencal N, Mitry E, Pilliere R, Lepere C, Gerardin B, Petit J, Gandjbakhch I, Rougier P, Dubourg O: Prevalence of patent foramen ovale and usefulness of percutaneous closure device in carcinoid heart disease. Am J Cardiol 2008;101:1035-1038.

124 Arnold R, Chen YJ, Costa F, Falconi M, Gross D, Grossman AB, Hyrdel R, Kos-Kudla B, Salazar R, Plockinger U: ENETS consensus guidelines for the standards of care in neuroendocrine tumors: follow-up and documentation. Neuroendocrinology 2009;90: 227-233.

125 Moertel CG: Karnofsky memorial lecture. An odyssey in the land of small tumors. J Clin Oncol 1987;5:1502-1522.

126 Delle Fave G, O’Toole D, Sundin A, Taal B, Ferolla P, Ramage JK, Ferone D, Ito T, Weber W, Zheng-Pei Z, De Herder WW, Pascher A, Ruszniewski P; all other Vienna Consensus Conference participants: ENETS consensus guidelines update for gastroduodenal neuroendocrine neoplasms. Neuroendocrinology 2016;103:119-124.
127 Ramage JK, De Herder WW, Delle Fave G, Ferolla P, Ferone D, Ito T, Ruszniewski P, Sundin A, Weber W, Zheng-Pei Z, Taal B, Pascher A; all other Vienna Consensus Conference participants: ENETS consensus guidelines update for colorectal neuroendocrine neoplasms. Neuroendocrinology 2016; 103:139-143.

128 Pape UF, Niederle B, Costa F, Gross D, Kelestimur F, Kianmanesh R, Knigge U, Öberg K, Pavel M, Perren A, Toumpanakis C, O’Connor J, Krenning E, Reed N, O’Toole $D$; all other Vienna Consensus Conference participants: ENETS consensus guidelines for neuroendocrine neoplasms of the appendix (excluding goblet cell carcinomas). Neuroendocrinology 2016;103:144-152.

129 Falconi M, Eriksson B, Kaltsas G, Bartsch DK, Capdevila J, Caplin M, Kos-Kudla B, Kwekkeboom D, Rindi G, Klöppel G, Reed N, Kianmanesh R, Jensen RT; all other Vienna Consensus Conference participants: ENETS consensus guidelines update for the management of functional pancreatic neuroendocrine tumors and non-functional pancreatic neuroendocrine tumors. Neuroendocrinology 2016;103:153-171.

130 Pavel M, O’Toole D, Costa F, Capdevila J, Gross D, Kianmanesh R, Krenning E, Knigge U, Salazar R, Pape UF, Öberg K; all other Vienna Consensus Conference participants: ENETS consensus guidelines update for the management of distant metastatic disease of intestinal, pancreatic, bronchial neuroendocrine neoplasms (NEN) and NEN of unknown primary site. Neuroendocrinology 2016;103:172-185.

131 Garcia-Carbonero R, Sorbye H, Baudin E Raymond E, Wiedenmann B, Niederle B, Sedlackova E, Toumpanakis C, Anlauf M, Cwikla JB, Caplin M, O’Toole D, Perren A; all other Vienna Consensus Conference participants: ENETS consensus guidelines for high-grade gastroenteropancreatic neuroendocrine tumors and neuroendocrine carcinomas. Neuroendocrinology 2016;103: 186-194. 